\title{
EL FERROCARRIL DE CORDOBA A LA CUENCA HULLERA DE ESPIEL Y BELMEZ (1852-1880)
}

JOSE MORILLA CRITZ

Universidad de Alcalá de Henares

\section{Introducción}

Este trabajo pretende ser una aportación al conocimiento de las vicisitudes de la construcción de una de las líneas ferroviarias andaluzas de trayectoria más compleja en el siglo xIx, completando de esta forma otros trabajos que tratan de la misma, especialmente los de P. Tedde ${ }^{1}$. Se centra, sobre todo, en los aspectos financieros de la construcción y en la pregunta sobre las motivaciones que tuvieron los grupos empresariales andaluces involucrados para interesarse en el negocio. Se integra, pues, este pequeño estudio en el complicado, y siempre actual, tema de la historia económica andaluza, de las actitudes empresariales ante las posibilidades económicas de la región. Profundizar en todo ello ha requerido utilizar una fuente no empleada hasta ahora en los trabajos sobre esta línea, como son los expedientes y documentos sueltos manuscritos de concesión, subvención y construcción, conservados en el Archivo del Ministerio de Obras Públicas o depositados por éste en el Archivo General de la Administración.

La primera nota sobre la problemática que resultó ser la construcción de este ferrocarril carbonero viene dada por el hecho de que la primitiva concesión data de 1856 y la línea no entró en explotación hasta 1873. Este período tan dilatado permite observar a través de los avatares de la concesión y de la construcción de esta línea el problema energético general de la Andalucía de la época, la actitud de la Administración pública ante unas actividades privadas como eran las construcciones ferroviarias y, naturalmente, la situación financiera de España, y especialmente de Andalucía, desde la

1 Tedde, P. (1978 a). Este trabajo está elaborado fundamentalmente en base a la Compañía de los Ferrocarriles Andaluces, la documentación las Memorias sobre Obras Públicas. Aparte de este esclalegal de esta empresa y las Memorias limitadas referencias a esta línea en las recedor artículo, tan sólo tenemos Tedde, P. (198 b); Casares Alonso, A. (1973), que, obras generales de ferrocarriles: Tedde, P. (os minero-carbonfferos y sorprendentemente, no incluye este ferrocarnesas, y la obra clásica de Wais, $F$. utiliza básicamente publicaciones oficiales impresas, y la obra clásica de Wals, (1974), cuyas fuentes no revela. 
crisis de 1866; elementos todos que constituyeron el marco en el que jugaban los intereses privados, buscando la máxima rentabilidad a sus capitales.

En la década de los años cuarenta del siglo xIx se empezó a manifestar en España un decidido interés por la explotación del carbón mineral, lo que iba ligado a la progresiva generalización de las máquinas de vapor en la industria textil, a los primeros intentos de sustituir el carbón vegetal en la producción siderúrgica ${ }^{2}$, a los comienzos de la navegación a vapor y de las fábricas de gas en las ciudades y, naturalmente, a los inicios (más deseos que realizaciones prácticas) del ferrocarril en la Península, cuya primera línea se construyó entre 1843 y $1848^{3}$. A estos hechos hay que unir también las razones estratégicas de los gobiernos desde 1921, que consideraban el autoabastecimiento nacional de carbón como prioritario, con el fin de contar con autonomía energética para las marinas de guerra y mercante en caso de conflicto. Desde los años cuarenta, a la razón estratégica se unían, para sostener una alta protección del mercado interior, la presión de los intereses de las explotaciones carboníferas asturianas ${ }^{4}$ y también la influencia en una Administración pública arcaica de concepciones del crecimiento económico de tipo «neomercantilistas», propias de las naciones rezagadas en la revolución industrial.

El ferrocarril no era solamente el más esperanzador consumidor de carbón mineral, sino que como medio de transporte mostraba en España, también para el caso de los productos carboníferos, una manifiesta «indispensabilidad ${ }^{5}$ a mediados del siglo xIx. Los criaderos, normalmente, se encontraban lejos de los principales centros potenciales de consumo, constituidos por los puertos marítimos, los núcleos industriales y las grandes poblaciones, que hasta el último cuarto del siglo xIx se concentraban, con la excepción de la aglomeración demográfica madrileña (también alejada de cualquier criadero), en las zonas mediterránea, suratlántica y en el lado oriental del Cantábrico. Ningún otro medio de transporte terrestre de la época podría competir, en las grandes distancias, con el ferrocarril en el transporte en grandes cantidades de una mercancía barata como el carbón.

El interés más temprano por un ferrocarril carbonero, lógicamente, se despertó en Asturias. Este dio lugar al ferrocarril Langreo-Gijón, que fue corrcedido en 1844 y obtuvo la primera subvención del Estado a una compañía ferroviaria en 1849, aunque no fuera, finalmente, construido hasta

2 Como bien se sabe, este caso precisamente sería de extraordinaria importancia en los años cuarenta para la siderurgia andaluza. Véanse al respecto Nadal, J. (1972) y García Montoro, C. (1978).

${ }^{3}$ Barcelona-Matar6́, concedida en 1843.

- Véase al respecto Nadal, J. (1975), pp. 122-154.

s En torno al "axioma de la indispensabilidad", véase Fogel, R. W. (1964). Para España, las consideraciones que en torno a él hace Tortella, G. (1981), p. 113. 
$1853.56^{\circ}$. Pero por esta época también hubo expectación por los criaderos de carbón mineral de la cuenca cordobesa de Bélmez y Espiel, manifestándose en hechos desde 1845, cuando se iniciaron los primeros proyectos de extracción de mineral de modo continuo ${ }^{7}$. Hasta 1869 , los propietarios mineros de la zona tuvieron sus esperanzas puestas en la capacidad de consumo de las instalaciones industriales de la mitad sur de España, en los ferrocarriles que se construían y en la navegación por el Mediterráneo. Por su parte, los empresarios siderúrgicos del Sur confiaron hasta 1861-65 en que esos carbones fueran capaces de compensar la diferencia de costes en su contra que estaba sufriendo la producción de sus instalaciones desde 1845 en relación a la naciente siderurgia asturiana, tanto por la mayor baratura de los carbones del Norte como por la imposibilidad de convencer al poder central para que eliminara la protección de que gozaban los carbones nacionales frente a los ingleses ${ }^{8}$.

No es de extrañar, pues, que en los diferentes solicitantes, concesionarios $y$ constructores que se sucedieron en las líneas que habrían de partir de estos criaderos se encontraran involucrados concesionarios de minas, potenciales consumidores, inversionistas estrictamente ferroviarios y simples especuladores; deslumbrados todos por el «gran futuro» de la cuenca y del transporte de sus productos, sobre todo cuando el Estado, desde 1856, mostró un preferente interés por la movilización de esa riqueza. Pero, curiosamente, no sería en todo ese período (1852-1868), de aparentes buenas perspectivas, cuando el ramal ferroviario más prometedor de esos criaderos (Córdoba-Bélmez) se viera construido, sino solamente a partir de 1869 , en una época en que parecería más claro que las antiguas esperanzas de competitividad de esos carbones caerían ante la política librecambista y, a la vez, se tenía ya un conocimiento más exhaustivo que en 1852 de las limitaciones técnicas y económicas del carbón de esta cuenca. Y entonces, además, la construcción del ferrocarril fue un pequeño gran negocio para los empresarios andaluces involucrados. La lógica de este proceso en la situación general de la economía andaluza de la época creemos que se manifiesta en las páginas que siguen.

\section{Proyectos fallidos: un negocio de dudosa rentabilidad}

En los diecisiete años transcurridos entre 1852 y 1869 hubo tiempo para que fueran muriendo las exageradas esperanzas de rentabilidad con que nació

- Véase Cordero, R., y Menéndez, F. (1978), pp. 233-234. También, Nadal, J. (1975) p. 132.

7 Garcia García L. (1979) p. 530.

- Véase Nadal J. (1972), pp. 44-45. 
la idea de un camino de hierro minero-carbonífero en la zona. Los cálculos económicos iniciales se fueron demostrando erróneos a medida que pasaban los años, sin que el Estado, muy intervencionista en el tema de los ferrocarriles, por otra parte, considerara de su incumbencia el plantearse el problema económico de la línea. Los sucesivos proyectos de mejora del trazado acababan quedando obsoletos y siempre susceptibles de mejora, ante la evolución tecnológica de la industria ferroviaria y el abaratamiento continuado de los carbones de importación para la franja costera andaluza. Estas circunstancias, unidas después a la crisis financiera de 1866, daban lugar a que los sucesivos concesionarios (que no serán más que ampliaciones de un primitivo núcleo de promotores) tuvieran dificultades para obtener los fondos precisos en el mercado de capitales. Es de destacar también en estos años la falta de interés efectivo por la línea por parte del gran capital andaluz.

La primera proposición relacionada con la construcción de una línea que uniera los criaderos con Córdoba data de 1852, hecha por los hermanos Mamby, que elevaron una petición al Ministerio de Fomento sobre un complejo ferroviario, en cuyo estudio se habían ocupado desde 1851, con la finalidad de facilitar la exportación de los productos andaluces hasta el centro de España y Valencia y, en especial, con la de «dar salida al carbón de las minas de Espiel y Bélmez». Se basaba el proyecto en una línea troncal entre Sevilla y Córdoba, con dos ramales-al Pedroso y Ecija y atro desde Córdoba a los criaderos carboníferos de Espiel y Bélmez, con la posibilidad también de extender el ramal de Bélmez hasta Almadén, para facilitar la extracción de los productos de sus minas; la del Pedroso hasta Cazalla, para los de Badajoz; el de Ecija hasta Loja y Antequera, y el ramal principal (CórdobaSevilla) hasta Andújar y Jaén. Como ellos mismos expresaban, ese camino de hierro sería el núcleo de todos los que se construyeran desembocando en el valle del Guadalquivir. Los citados ingenieros decían contar, para llevar a cabo sus planes, con el apoyo financiero de varios capitalistas y contratistas extranjeros y con el de algunas de las más respetables casas de Sevilla ${ }^{9}$.

Este proyecto entraba de lleno en la estructura de la planificación ferroviaria del proyecto de ley de Reinoso ${ }^{10}$, que intentaba poner orden, como otros anteriores, ante la avalancha de solicitudes particulares de estudios o concesiones. Por R. O. de 11 de julio de 1855 se concedió permiso a Eduardo Olivier Mamby para realizar los estudios de la línea Córdoba-Bélmez. Fruto de estos estudios debieron ser los primeros planos de esta línea, adqui-

- Instancia de los Sres. Mamby; entre los papeles adjuntos a los expedientes. Leg. 108 (numeración de la Dirección General de Transportes Terrestres): Ferrocarril Córdoba-Bélmez (ésta es en adelante la documentación citada).

${ }^{10}$ Mateo del Peral, D. (1978), p. 76. 
ridos después por Francisco Romá, de un camino de hierro de 65 kilómetros desde el Albardado hasta Ventas de Alcolea "

Hay una correlación entre estos comienzos inciertos del ferrocarril y una fiebre minera en los criaderos carboníferos de Bélmez pensando en el futuro. Tal como expresa Lorenzo García, había surgido «un fuerte movimiento de especulación, que se refleja en la creación de numerosas sociedades hasta 1852 , siendo la mayoría de simple nombre sin llegar a realizar actividad extractiva" ${ }^{12}$.

Tras la Ley General de Ferrocarriles de 1855, se concedió a Francisco Romá y Cía. ${ }^{13}$, el 18 de junio de 1856, la construcción de un ferrocarril entre Bélmez y Ventas de Alcolea, que, entre otras características interesantes, tenía la de proyectarse para ser arrastrado por caballerías, proyecto que puede parecer desfasado técnicamente a estas alturas del siglo xIx y, en cierto modo, inexplicable para una línea que habría de transportar precisamente carbón. No obstante, se dejaba abierta la posibilidad en la concesión a la utilización de locomotoras en la parte menos inclinada del recorrido y a hacer los estudios para, en el futuro, poder sustituir el proyecto por otro con tracción a vapor, a medida que progresasen las locomóviles. Tal como correspondía a una línea de servicio particular $y$, por tanto, no incluida en la planificación estatal, la concesión no llevó aparejada concesión alguna.

Las dificultades que tuvo este proyecto para obtener apoyo financiero, que el concesionario achacaba a la paralización mercantil de esos años y a los sucesos políticos de 1855-56, retrasaron la inauguración de las obras hasta abril de 1857 . Pero ya en ese momento el proyecto de tracción animal había quedado obsoleto ante el conocimiento de la posibilidad de introducir locomotoras en todo el trayecto, incluso en los tramos más inclinados. También desde entonces había ya otros intereses que pugnaban por obtener la concesión de una línea que se declarara de interés general (que llevaba aparejada subvención) que uniera la línea de Portugal con Córdoba, cosa que se discutía en las Cortes desde julio de 1857.

Los mayores costes que implicaba la construcción de un ferrocarril a vapor hacían precisos nuevos capitales, que Romá y Cía. intentaron obtener

"Se halla recogido en una "Relación de gastos hechos por Francisco Romá y Cía. desde 4 de enero de 1854 a 4 de julio de 1860" que Romá aportó a la Cía. del Ferrocarril de Córdoba a Espiel y Bélmez. Documentación citada.

12 García García, L. (1979), p. 530.

13 Francisco Romá era uno de los socios que junto a Joaquín Figueras habian obtenido la concesión del ferrocarril Córdoba-Sevilla, con intereses mineros en la cuenca de Bélmez. Junto a Romá aparecen involucrados en la sociedad ferroviaria, primero González Bravo y los hermanos Girona, y más adelante también José de Salamanca. (Según el libro del expediente de concesión, al referirse a la consignación de las partidas correspondientes a la garantía, pp. 12-14, 25-28 y 48. Documentación citada.) 
con la creación de la Sociedad Anónima del Ferrocarril Córdoba-Espiel-Bélmez. Pero era lógico que fuera difícil obtener adhesiones a esta sociedad para llevar a cabo el primitivo proyecto de Romá mientras existiera la posibilidad de que se aprobara otro ferrocarril paralelo a éste y subvencionado por el Estado. En estas condiciones, Romá y Ć́a. fueron obteniendo prórrogas para nuevos estudios y, en marzo de 1861, consiguieron constituir la «Compañía del Ferrocarril Córdoba-Espiel-Bélmez», con un pequeño capital (784.938 pesetas desembolsado, más 893.000 pesetas de aportación en obras de Romá y Cía., totalmente inútiles, pues eran para el ferrocarril de tracción animal). Con ello se quería emprender un proyecto de construcción, elaborado por el ingeniero Sandino en 1862, de un ferrocarril entre Bélmez y Córdoba de 73 kilómetros de longitud, con un presupuesto de $24.792 .985,25$ pesetas, con el que se calculaban obtener los siguientes rendimientos anuales:

Por el transporte de 369.000 tns. de carbón a 20 cts. de real por tn. $y \mathrm{~km} . \ldots \ldots \ldots \ldots \ldots \ldots \ldots \ldots$

Por el transporte de 4.000 tns. de combustible a $1,90 \mathrm{rls}$.

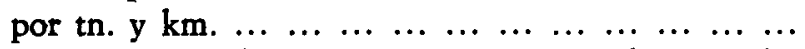
1.341 .250 pts.

Por el transporte de 35.000 tns. en materiales para las minas de la cuenca y las de Almadén a 0,65 rls. por $\mathbf{k m} . \ldots \ldots \ldots \ldots \ldots \ldots \ldots \ldots$

Por el transporte de 80.000 viajeros a 0,30 rls. por $\mathrm{km}$. $\begin{array}{lllllllllllll}\text { y cabeza } & \ldots & \ldots & \ldots & \ldots & \ldots & \ldots & \ldots & \ldots & \ldots & \ldots & \ldots & \ldots\end{array}$

$\begin{array}{llllllllllll}\text { Total } & \ldots & \ldots & \ldots & \ldots & \ldots & \ldots & \ldots & \ldots & \ldots\end{array}$

Gastos de explotación $\ldots \ldots \ldots \ldots \ldots \ldots$

139.852 pts.

$417.987,5$ pts.

441.000 pts.

$2.340 .089,5$ pts. $1.214 .992,0$ pts.

Beneficios año

$1.125 .097,5$ pts.

Que para el capital a invertir significaría un rédito del 4,54 por $100^{14}$.

Es interesante resaltar que el ingeniero jefe de la División de Sevilla, aun cuando juzgaba técnicamente adecuado el proyecto de Sandino, lo consideraba económicamente un despropósito y, como mínimo, entendía que no se había hecho un estudio detallado del consumo potencial de carbón de las provincias de Cótdoba, Málaga, Jaén y Granada, en las que podría mostrar ventaja frente a otros proyectos ferroviarios posibles de Bélmez a la línea de Ciudad Real-Badajoz. Por ello, este ingeniero propuso que se exigiera un estudio económico detallado del ferrocarril. Sin embargo, tanto el

\footnotetext{
14 Datos incluidos en el informe del ingeniero Antonio de Palacio, sobre el proyecto de variación del trazado propuesto por la compañia concesionaria, en 15 de febrero de 1867. (Documentación citada.)
} 
Negociado de Ferrocarriles como la Dirección General de Obras Públicas y la Junta Consultiva de Caminos, Canales y Puertos despreciaron las oportunas recomendaciones de la División de Sevilla, con un criterio burocratista, y llegaron hasta llamar la atención al ingeniero jefe por su excesivo celo en los asuntos económicos:

Negociado: «El Ingeniero Jefe... equivocando su misión en el presente caso se extiende en consideraciones verdaderamente inútiles en la actualidad..."

Dirección General: «... el activo y celoso Jefe de la División que ha examinado el proyecto en vez de dedicarse al estudio especial del trabajo que se le recomendaba... se entretiene en examinar minuciosa y prolijamente las condiciones económicas...»

Esta visión burocrática fue también la que sostuvo la Junta Consultiva ${ }^{15}$. De esta manera, la Administración aprobó a sabiendas un proyecto económicamente inviable, con el argumento de que ésta era una línea no subvencionada y que, por tanto, su rentabilidad era un asunto del exclusivo interés de los concesionarios. Tal era la utilidad del pesado intervencionismo estatal en la materia.

Contradictoriamente, durante este tiempo el tema de la extracción de los carbones de Bélmez había pasado a ser un tema que preocupaba crecientemente al Estado, ante el aumento del consumo ferroviario ${ }^{16}, \mathrm{y}$, por supuesto, a los propietarios de la cuenca, en la que habían penetrado nuevas sociedades con intereses en ferrocarriles, como Parent-Schaken y Cía. También hacia 1864-65 parecían abrirse nuevas perspectivas a la salida de los carbones hacia el Mediterráneo Sur, a través del ferrocarril Córdoba-Málaga, cuya construcción estaba a punto de terminarse. En Málaga, al margen dẹl problema carbonífero de sus fábricas, se había abierto una gran esperanza en el aprovisionamiento de los buques que habrían de pasar por el proyectado canal de Suez y que deberían ser provistos de combustible en puertos de escala.

Todas estas preocupaciones y esperanzas terminaron por producir la autorización de construcción, con derecho a subvención, de dos líneas ferroviarias desde las cuencas cordobesas (una hasta la línea del ferrocarril Ciudad Real-Badajoz y otra a la del Córdoba-Sevilla) y se canceló, de mutuo acuerdo con la sociedad originaria, la concesión a Romá y Cía. En cualquier caso, éste reconoció en enero de 1864 no haber podido obtener capital suficiente para llevar a cabo su proyecto, a pesar de la prórroga y las posibilidades de modificación del mismo, aparte de resultarle personalmente muy oneroso el

is Los textos del Expediente de construcción, tomo 1, pp. 22-23 y 28 (reverso)-29. (Documentación citada.)

16 En 1864 había ya construidos en España 3.991 kilómetros de vías térreas. 
empeño, pues la sociedad le debía, por pagos propios de gastos del nuevo proyecto, 699.036 pesetas. Las obras construidas (sólo de explanación y fábrica) en estos primeros siete años transcurridos desde la inauguración de los trabajos habían sido mínimas y, como ya se ha dicho, incluso resultarían inútiles para otros proyectos posteriores.

Si se han de buscar las razones del primer retraso en la construcción de este ferrocarril, se puede aducir hasta 1864 la falta de capitales; pero hay que añadir inmediatamente que, en medio de la fiebre ferroviaria existente, aquélla estuvo motivada por las contradicciones de una política ferroviaria que no sólo permitía, sino que incluso alentaba, el planteamiento de un ferrocarril económicamente inviable, con el argumento de que no era asunto que debía atañer al Estado, al tiempo que creaba la expectativa de la concesión de otras líneas paralelas competidoras y subvencionadas, que, por otra parte, tampoco llegaron a manifestarse en proyectos concretos hasta después de 1863. Pero es que, además, cuando el Estado sacó a concesión una nueva línea subvencionada en 1863 , lo hizo para el mismo proyecto y presupuesto de la concesión rescindida, a pesar de su antieconomicidad manifiesta. A la futura sociedad concesionaria, por otra parte, se le imponía la carga de abonar a la Sociedad del Ferrocarril Córdoba-Espiel-Bélmez las obras ejecutadas (1.434.677 pesetas), lo que constituía una prima para la reincidencia en el proyecto inicial.

Las deficiencias técnicas y económicas de este proyecto, unidas a las dificultades financieras del momento, van a dar lugar a la más complicada historia de la línea Córdoba-Bélmez entre 1865 y 1869, sin que tampoco se avanzara gran cosa en su construcción. Una compañía de crédito (la Compañia Internacional de (rédito), a través de uno de sus accionistas y directivos, José Sabater, obtuvo en subasta la concesión de la construcción y explotación de la línea en mayo de 1865 , con una subvención directa para el proyecto Sandino de 7.250 .000 pesetas. En ese momento, la Compañia Internacional de Crédito tenía escriturado un capital social de 50 millones de pesetas, del cual tenía realizado solamente algo más de 7,5 millones.

El pago a la Sociedad del Ferrocarril C.-E.-B. por las obras ejecutadas se hizo mediante ampliación del capital de esta sociedad, que en lugar de disolverse emitió 7.680 acciones de 1.900 reales, que fueron suscritas por la Compañia Internacional de Crédito. Miembros directivos de esta compañía pasaron a formar el nuevo Consejo de Administración de la Sociedad del Ferrocarril C.-E.-B. en abril de 1865 . De esta manera, la antigua sociedad pasó a tener un capital nominal de 7.457 .500 pesetas, dividido en 15.700 acciones. Al mismo tiempo, se celebró un convenio entre las dos empresas por el que la concesión era traspasada nuevamente a la Sociedad del Ferrocarril C.-E.-B. y ésta contrataba con la Internacional de Crédito la construc- 
ción de la línea por 23,75 millones de pesetas ${ }^{17}$. De esta manera no fue preciso hacer pago alguno por las obras ejecutadas, que, a su vez, podían servir de garantía ante la Administración para cobrar la subvención sin nuevos aportes por los nuevos concesionarios. Pero, en resumidas cuentas, la nueva aportación de capital efectivo sería, cuando la Compañía Internacional de Crédito la satisfaciera, el 10 por 100 de las 7.680 nuevas acciones, siendo el resto de las aportaciones las obras realizadas por los anteriores concesionarios, inservibles en su mayor parte. Cuando todas las acciones estuvieran desembolsadas, la sociedad esperaba contar con 6.735 .500 pesetas ( 722.000 eran para pagos de los estudios anteriores), que, unidas a los 7.250 .000 pesetas de subvención, más las obligaciones que podría emitir, harían unos recursos de 27.971.000 pesetas, cantidad superior al presupuesto del proyecto.

Por tanto, hay que tener en cuenta que, aparte de la subvención estatal, los recursos efectivos para la construcción de la línea dependían de la liberación del dinero por la Compañía Internacional de Crédito (que, por su parte, tenía desembolsada una porción ínfima de su capital) y del mercado de obligaciones. Como se deduce del Balance de la Sociedad del Ferrocarril, la Compañia Internacional de Crédito era la depositaria del importe de las acciones suscritas, y la Sociedad del Ferrocarril Córdoba-Espiel-Bélmez había emitido solamente 5.169 obligaciones, por un importe de 859.700 pesetas.

Balance de situación de la Compañía del Ferrocarril de Córdoba a Espiel y Bélmez al 30 de septiembre de $1866^{18}$

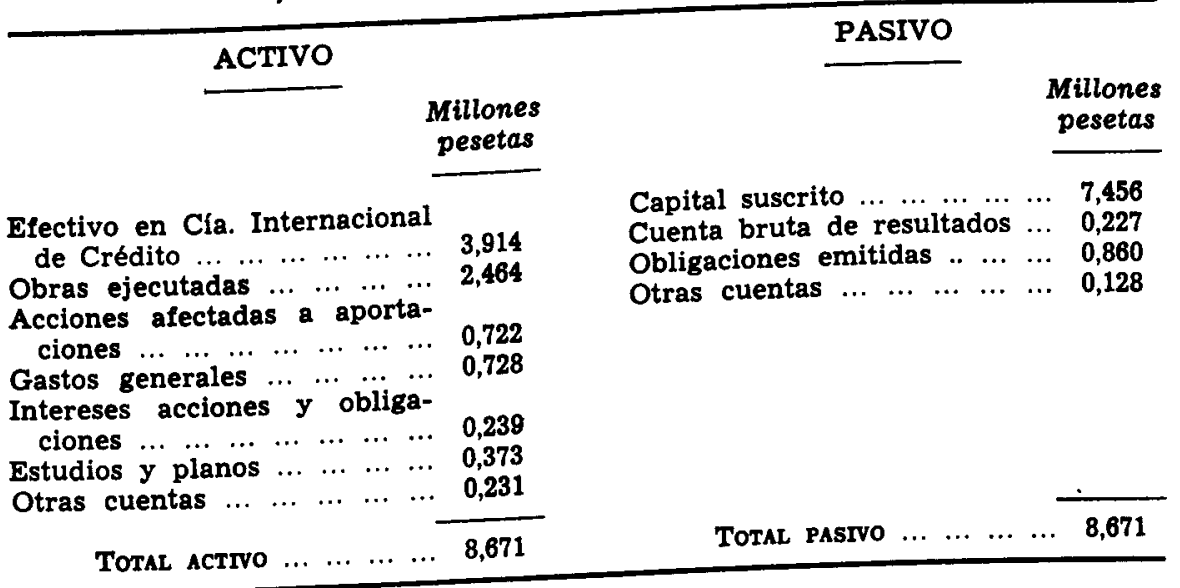

17 La diferencia con el presupuesto inicial se debía a la intención de extender la línea hasta Almorchón, proyecto que la sociedad del ferrocarril tenía ya en estudio.

is Incluido en la documentación cítada. 
Todo esto da idea de la debilidad financiera inherente a esta concesión, que, es interesante resaltarlo, no parece tener aportación de capital extranjero, a pesar del sonoro nombre de Compañia Internacional de Crédito, que, de cualquier forma, daría en quiebra muy pronto.

Las obras se habían reiniciado el 30 de junio de 1865; pero, en las condiciones financieras descritas, la crisis de 1866 se cebó en ambas sociedades, tan dependientes de fuentes ajenas de financiación. Por otra parte, a medida que se hacían los estudios para mejorar el trazado y hacerlo económicamente aceptable al capital, las obras no podían realizarse, con lo que no era posible obtener tampoco cobros de la subvención estatal. En estas condiciones, las obras que se habían reiniciado volvieron a paralizarse a finales de 1866 . La Sociedad del Ferocarril sólo confiaba entonces en poder obtener anticipos de subvención desde el Gobierno y que éste le concediera prórrogas para hacer modificaciones en el trazado que lo mejoraran económicamente.

En esta fecha, la Inspección de Sevilla seguía convencida de que el proyecto inicial de Sandino, aun mejorado por los nuevos estudios (que reducían el coste de establecimiento a 21.011 .004 pesetas), era económicamente un error, porque «en las unidades de tráfico hay mucha exageración», ya que la cifra de producción de carbón en el año era de 11.000 toneladas, en lugar de las 369.000 previstas en el proyecto Sandino; considerando que, aunque se alcanzaran éstas, con ellas posiblemente no quedaría beneficio alguno, porque mientras tanto se irían acumulando los gastos financieros del capital y de las obligaciones. Por ello, creía que la Sociedad del Ferrocarril C.-E.-B. no podría llevar a cabo el proyecto a la larga, por lo que recomendó no aprobar tampoco el proyecto presentado modificando ciertos tramos y obligarle a nuevos estudios que hicieran más económica la construcción, así como a aportar datos suficientes sobre las posibilidades económicas de la línea ${ }^{19}$, cosa que no fue, una vez más, atendida por la Administración:

Negociado: «El Ingeniero Jefe de la División de los Ferrocarriles de Sevilla, insiste nuevamente en la conveniencia de adoptar para el ferrocarril de Espiel y Bélmez a Córdoba un trazado económico... El Negociado que ha demostrado la inoportunidad e inconveniencia de semejante propuesta... no tiene por qué presentar a la autoridad nuebas (sic) consideraciones relativas a este asunto.... ${ }^{20}$.

1' Informe del ingeniero jefe de la División de Sevilla, Antonio de Palacio, el 15 de febrero de 1867. Documentos sueltos y Expediente de construcción, tomo 1 , páginas 50 (reverso) -57 .

20 Expediente de construcción, tomo 1, pp. 62-64. 
Solamente se recomendó una mayor celeridad en las obras, se aprobó la nueva modificación de trazado y se concedió una prórroga de terminación del ferrocarril de dieciocho meses (hasta el 8 de octubre de 1869). Mientras tanto, el abandono en que quedaron las obras ejecutadas hizo que se desvalorizaran hasta 997.964 pesetas, y la Compañía Internacional de Crédito desapareció de la escena, en quiebra, pasando el derecho de construcción, el 10 de mayo de 1867 , a la compañía de seguros generales denominada $E l$ Monte Pio Universal, acreedora de aquélla. Esta nueva sociedad contrató con García Goyena la construcción, con la aprobación de la Sociedad del Ferrocarril $^{21}$, en 17,5 millones de pesetas, 14 de los cuales habría de cobrar en efectivo.

Las cláusulas de este contrato son muy interesantes, pues reflejan ya que el único garante de la construcción del ferrocarril había llegado a ser el Estado, con una subvención que sería proporcionalmente cada vez mayor a medida que se presentaran proyectos más económicos (posibilitadós tanto por la evolución técnica de los sistemas de construcción y del material como por la reducción de éste y el trazo depresivo de los precios durante algunos años) ${ }^{22}$. El nuevo constructor iría cobrando directamente del Gobierno la subvención directa y adicional a medida que avanzaran las obras, y las cantidades así obtenidas las descontaría de la cantidad a obtener del Montepío. Este, por tanto, habría de pagar a Goyena solamente unos cinco millones de pesetas en efectivo y el resto en obligaciones de la Compañía del Ferrocarril, cantidad que se reduciría caso de ser menor el coste de lo previsto de los últimos 28 kilómetros de la vía, entre el Castillo de Bacar y Córdoba, sobre el que se estaban realizando estudios.

Goyena, con el mismo criterio de trabajar exclusivamente con dinero público y sin haber llevado a cabo obra alguna, subcontrató, a su vez, en octubre de 1867 con uno de los grandes constructores ferroviarios andaluces de la época, Joaquín de la Gándara, las obras de explanación en 32 kilómetros (Bélmez-La Alhondiguilla) por dos millones de pesetas, a cobrar directamente por Gándara del Estado al ir ejecutando los trabajos, que también tendría derecho a proponer a la Administración las modificaciones que estimara oportunas en el proyecto ${ }^{23}$.

21 Escritura del contrato de construcción del ferrocarril Córdoba-Bélmez, otorgada por el "Montepo Universal" a favor de don Eduardo García Goyena, extendido ante el notario del ilustre Colegio de Madrid don Cipriano Pérez Alonso Pizarro, 9 de agosto de 1867. La diferencia en el presupuesto está en que García Goyena contrata las obras que faltan, según el nuevo proyecto, y con nuevos precios.

22 Véase Casares Alonso, A. (1973), p. 305.

${ }^{23}$ Quedó manifestado efectivamente en la Ley de 27 de mayo de 1868 por la que se autorizó la modificación del trazado en el proyecto de construcción en el 
Este último contrato tuvo gran importancia para el futuro de la línea, no sólo porque por primera vez se cumplió lo previsto, sino porque a partir de entonces se demostró que la construcción de esta línea podía ser en sí misma un negocio extraordinario. Gándara construyó esas obras por 1.434 .366 pesetas, lo que significaba un beneficio neto a realizar exclusivamente con la subvención del Estado de 565.634 pesetas $(39,4$ por 100) (a pesar de que éste no cobrara al término de las obras más que 1.371 .614 pesetas y quedara un crédito a su favor por el resto, que cobraría un año más tarde de nuevos constructores). Este negocio estaba al alcance de la mano de aquellos personajes que, en medio de la penuria financiera extendida tras la crisis de 1866, tuvieran un mínimo de capital circulante con que hacer frente a los primeros anticipos de pago de jornales y acopios, hasta tanto se empezaban a recibir los pagos de subvención, y un cierto crédito en el extranjero para concertar la adquisición de los materiales. Ello ocurría, además, en un momento en que muchas circunstancias adversas se habían unido para hacer difíciles y arriesgados otros negocios del capital andaluz.

La Administración era consciente de las características de este negocio de construcción. La Junta Consultiva, el 12 de marzo de 1969, tras reconocer el avance de las obras con Gándara, expresa que:

«Este resultado, a primera vista halagüeño, no lo es en realidad, puesto que lo único que se ha conseguido es que por la suma de 800.000 escudos que va a dar como anticipo de subvención el Estado a un contratista, ha ejecutado esta obra, cuyo valor excede poco respectivamente de aquella cantidad ${ }^{24}$.

Este ferrocarril, pues, era una pequeña muestra de cómo en esos años de crisis financiera, y, contradictoriamente, de gobiernos que defendian los principios del liberalismo económico, también el Estado primaba la especulación con obras públicas, cosa que, según Tortella, había tenido graves consecuencias para la industrialización del país en el período inmediatamente anterior (1855-1866) ${ }^{25}$. Así, la crisis, con el consiguiente descenso de precios y aumento de la mano de obra parada, ofrecía en 1869 oportunidades extraordinarias para utilizar dinero público por parte de empresarios privados que no hubieran sido barridos por aquélla y no dependieran del mercado financiero para obtener otros fondos.

sentido más económico propuesto por Gándara, sin que ello modificara la subvención, a pesar de que disminuía la longitud del camino.

24 Expediente de concesión, tomo I, pp. 224 (reverso)-225.

${ }^{25}$ Tortella, G. (1975), pp. 338-340. 
Un negocio rentable: la entrada del gran capital andaluz en 1869

No era solamente la posibilidad de obtener un jugoso beneficio con la subvención del Estado la que actuaba, hacia 1869, a favor de la construcción del ferrocarril de los criaderos de Espiel y Bélmez. Contrariamente a lo que se podía pensar por parte de los defensores en la época del proteccionismo, las medidas liberalizadoras que se instauraron en España desde 1869 crearon condiciones idóneas para la explotación de los carbones de esta cuenca. En unión de la demanda internacional y de las medidas desamortizadoras del subsuelo ${ }^{26}$ de 1868 , produjeron una fiebre minera en Andalucía, muy señalada especialmente en la extracción de plomo de las provincias de Jaén, Murcia y Córdoba, que hicieron de España el primer productor mundial de este metal entre 1868 y $1897^{27}$. En el principal distrito minero andaluz de esta época, Linares, se realizó una verdadera "revolución industrial», en palabras de Franco Quirós, que ha cuantificado la evolución del número de máquinas de vapor puestas en funcionamiento y la potencia instalada en la ciudad, que pasaría, en este último caso, de $811 \mathrm{CV}$ en 1864 a 2.343 en $18788^{28}$. Algo similar ocurría en todo el distrito linarense y en las restantes zonas.

La instauración de una política librecambista favoreció en Andalucía la distribución de factores productivos a favor de las producciones en las que la región tenía ventajas absolutas y comparativas en el mercado internacional, que eran en esos años no sólo las minerales, sino parte de su agricultura de las comarcas interiores. Pero para movilizar esas riquezas eran precisas fuentes de energía y medios de transporte, necesidades que, a su vez, iban entrelazadas. Los carbones minerales, si bien estaba comprobado que los de procedencia inglesa no podían tener competencia en la franja costera, cuyos puertos habían sido en la primera mitad de siglo el centro de gravedad del crecimiento económico y aun industrial de Andalucía, por el contrario, no podían resistir la competencia de los de Bélmez y Espiel en las comarcas interiores de la región una vez que se les acumulaban los costes de transporte. Hay que tener en cuenta que en el año de la terminación del ferrocarril de estos criaderos, 1873, el precio de la tonelada de carbón de Bélmez en la estación de Córdoba era favorable en más de 20 pesetas al de importación, y Córdoba era ya el nudo de comunicaciones entre Andalucía oriental y occidental y de toda la región de Extremadura (otra importante zona minera). Así, pues, la «movilización» de la riqueza de la Andalucía interior, a la que nos hemos referido en otra ocasión ${ }^{29}$, primaba la explotación de los

${ }^{26}$ Nadal, J. (1975), pp. 90-105.

${ }^{2}$ Nadal, J. (1972), p. 60.

2 Franco Quirós, J. (1979), p. 514 y p. 525.

20 Morilla Critz, J. (1979), pp. 29-35. 
yacimientos carboníferos cordobeses y hacía de ellos, en 1869, un negocio de grandes perspectivas para los capitales disponibles.

Ante las favorables perspectivas acudió el capital extranjero, pero también el de origen andaluz, que, con una visión empresarial privada correcta a corto plazo, abandona actividades industriales y financieras de la franja costera, fundamentalmente en el área malagueña, con dificultades crecientes. Esto posibilitó que el pequeño pero estratégicamente importante ferrocarril de Córdoba-Bélmez fuera, finalmente, construido en breve plazo por el impulso de empresarios andaluces; concretamente, del gran grupo capitalista malagueño del siglo xrx: las sociedades Heredia, Larios y Loring, que si en años anteriores mostraron interés en este ferrocarril por las posibilidades de surtir de carbones a sus industrias siderúrgicas, en 1869 tenían ya otras razones mejor asentadas en la realidad de un mercado libre. Al respecto, es ilustrativo el claro paralelismo desde entonces entre la producción de carbón de la provincia de Córdoba (que llegó a ser casi del 25 por 100 de la nacional) y la de productos semielaborados de la industria plumbífera del interior de Andalucía:

Indices de producción de carbón y de plomo en barras, 1861-1879 (Base 100: 1869)

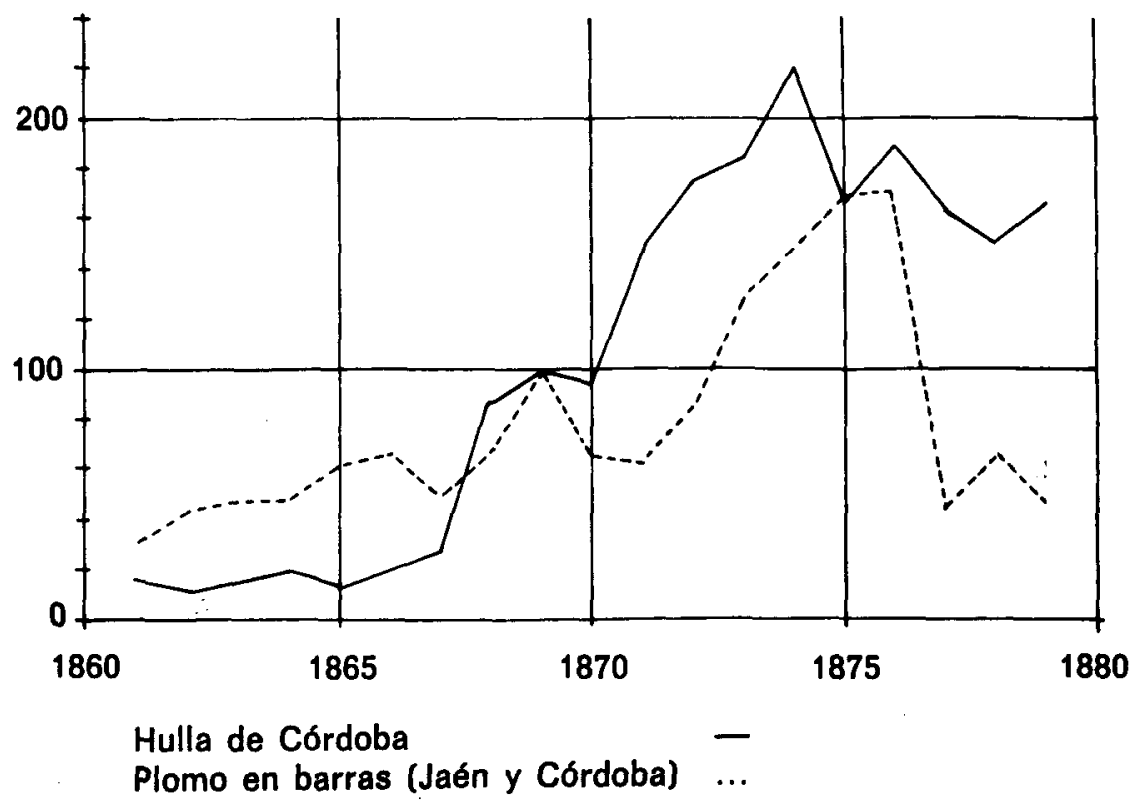

Fuerre: Según datos de Nadal, J. (1975). 
Las sociedades Heredia, Larios y Loring, mancomunadamente, se plantearon de forma integral la explotación de los carbones de Bélmez, en un momento de ruina de otras empresas de la cuenca, a la que les había llevado tanto la crisis financiera de 1866 en sí como la paralización de las obras del ferrocarril por los demás motivos aducidos, y pudieron obtener transferencias de negocios en muy buenas condiciones económicas. A mediados de 1869 arrendaron, con opción a compra, todas las explotaciones carboníferas de la principal empresa de la cuenca, Carbonera Española ${ }^{30}$, y, al mismo tiempo, celebraron un contrato de construcción del ferrocarril Córdoba-Bélmez con El Monte Pío Universal, que también estaba en dificultades financieras ${ }^{31}$, y con la Sociedad del Ferrocarril C.-E.-B. (en completa insolvencia), que dejaría también este negocio en sus manos.

El contrato con la Sociedad del Ferrocarril se celebró el 14 de agosto de 1869 , y englobaba en sí un nuevo proyecto de trazado del ferrocarril, presentado por el propio «Sindicato» malagueño, y una nueva modalidad de financiación con dinero público ${ }^{32}$. Por el mismo, Larios, Heredia y Loring se comprometían a terminar las obras entre Almorchón y La Alhondiguilla y hacerlas enteras desde aquí hasta Córdoba, y a proveer todo el material fijo y móvil, por una cifra de 14.250 .000 pesetas (sumando a ella el valor de las obras ejecutadas hasta entonces, $2.432 .329,75$ pesetas, el presupuesto inicial sufría una rebaja de más del 25 por 100 , sin que paralelamente se redujera la subvención estatal). Esta suma se pagaría con la subvención del Estado y con los futuros productos de la explotación.

Quedó establecido un sistema de cobro por parte de los nuevos constructores que reducía al mínimo para éstos los riesgos de quedar al descubierto ${ }^{33}$, a la vez que un remunerador interés por las partidas devengadas y no hechas efectivas, y quedaban en último caso como garantía de los constructores, por una parte, los rendimientos de la explotación, gestionada por

3o Según García García, L. (1979), esta empresa había concentrado en sus manos en 1868 gran parte de las propiedades mineras de otras sociedades. El 31 de julio de 1869 las Sociedades Heredia, Larios y Loring, de Málaga, celebraron con Carbonera Española un contrato de arrendamiento con opción a compra de todas sus propiedades por veinte años.

" En esta época el Montepío Universal estaba gestionado por una Junta de Intervención, y durante los años que duró la construcción del ferrocarril se vio requerida esta sociedad en varias ocasiones por acreedores que pretendían embargar la subvención.

32 La subvención directa sería cobrada por los propios constructores periódicamente, en cantidades iguales al montante de los certificados mensuales de obras ejecutadas.

${ }^{33}$ El valor de los materiales acopiados sería cargado en cuenta de la Sociedad del Ferrocarril en la misma forma que los constructores habrían de abonarlo a los proveedores: $2 / 5$ en el momento de hacer el pedido, $2 / 5$ al desembarcarlo en Málaga y $1 / 5$ al descargarlo en Córdoba. El tipo de interés era del 7 por 100. 
ellos mismos con carácter excluyente, y, por otra, el carácter refaccionario de la deuda que en su caso resultare (es decir, la preferencia de su crédito sobre cualquier otro). Además, la Sociedad del Ferrocarril C.E.E.B. se comprometía a depositar en poder del Gobierno todas las obligaciones emitidas $y$ en poder de la Sociedad del Ferrocarril y del Montepío, todas las que pudiere adquirir, y a no negociar más títulos hasta que no se extinguiera el crédito de constructores.

También se establecía que se había de obtener del Gobierno la aceptación de todas las cláusulas de este contrato y una prórroga del plazo de terminación de las obras de tres años y medio, en el plazo de veintiún días; quedando, en caso contrario, nulo el contrato. Esta era una forma de coaccionar al Gobierno, pues iba unida a presiones de la propia Sociedad del Ferrocarril, del Gobierno Civil, la Diputación, el Ayuntamiento y varios vecinos influyentes de Córdoba ${ }^{34}$, que se dirigieron a aquél haciéndole ver que ese contrato era la única esperanza que había de ver terminadas las obras del ferrocarril, dado el crédito que merecían esas tres casas mercantiles malagueñas. Unían al tradicional argumento de lo imprescindible de este ferrocarril, la necesidad de dar ocupación a muchos jornaleros andaluces y manchegos, «favoreciendo así el restablecimiento y conservación del orden públicos ${ }^{35}$.

Tras una serie de forcejeos ${ }^{36}$, consultas a la Junta Consultiva de Caminos, Canales y Puertos y al Consejo de Estado, el Consejo de Ministros acabó aceptando, casi en su totalidad, las condiciones impuestas por el «Sindicato» malagueño, aun cuando el asunto se prolongó hasta el 15 de febrero de $1870^{37}$.

${ }^{34}$ Instancia dirigida al Ministerio de Fomento por don Alejandro Mazarredo, director gerente de la Cía. del Ferrocarril Córdoba-Espiel-Bélmez en 20 de agosto de 1869 y Exposiciones enviadas por el gobernador, por el Ayuntamiento y por la Diputación de Córdoba en 19 y 30 de agosto de 1869. (Documentación citada.)

${ }^{3 s}$ De la Instancia citada de don Alejandro Mazarredo.

36 Entre las que estuvieron las gestiones personales directas del propio Jorge Loring ante el Ministerio, por lo que ante promesas verbales de éste se celebró el nuevo contrato antes del acuerdo del Consejo de Ministros.

${ }_{37}$ Resoluciones del Consejo de Ministros sobre el contrato con Loring el 15 de febrero de 1870:

1." Se concede prórroga de dos años y medio.

2. La compañía recogerá 7.000 obligaciones por lo menos de las 10.102 emitidas y las depositará en la Caja de Depósitos.

3." No se emitirán nuevas acciones ni obligaciones.

4." Unicamente se entregará por ahora el 80 por 100 del importe de los certificados de obra mensuales como subvención, y si se aumentase el depósito de obligaciones hasta completar las 4/5 partes, se entregará el total del importe de dichos certificados, entendiéndose que sólo se aplicará este objeto a la parte de subvención correspondiente a los 42 kilómetros entre Córdoba y La Alhondiguilla.

5. La liquidación de intereses que pueda tener lugar en su caso, por las cantidades anticipadas, se verificará y saldará con los últimos plazos o entregas de subvención que se deban hacer a la compañía.

6." La subvención directa para el resto del camino y la adicional equivalente 
Al haber quedado automáticamente anulado el contrato, se extendió otro nuevo el 12 de febrero, que recogía las leves modificaciones del Gobierno, y que fue firmado por Jorge Loring, lo cual no quiere decir que actuara en solitario. Existía entre los tres socios malagueños un convenio privado de actuar conjuntamente, que, para que quedara completamente legalizado, fue extendido en escritura una vez terminada la construcción del ferrocarril ${ }^{38}$.

En síntesis, las expectativas de los tres capitalistas andaluces en 1870 eran las de construir un ferrocarril de 71 kilómetros con 14.250 .000 pesetas del Estado (resto de la subvención directa y adicional que quedaba por cobrar), teniendo garantizado en todo caso que, aunque el coste de la construcción fuera menor, habrían de cobrar esos 14,25 millones junto con los intereses correspondientes. Y a nadie se le ocultaba la imposibilidad de que dos sociedades completamente descapitalizadas pudieran satisfacer algún día los 7,3 millones de deuda inicial con los constructores, máxime si no podían negociar ningún tipo de títulos en el mercado. Esto ya lo vieron claro los accionistas de la Sociedad del Ferrocarril C.-E.-B., que tras un cambio del Consejo de Administración, que eliminó de la dirección a los firmantes del contrato, intentaron en vano buscar apoyo del Gobierno para modificar el contrato con las sociedades Heredia, Larios y Loring ${ }^{39}$.

Aspectos financieros del negocio de la construcción, 1870-1880

Bajo la dirección de J. Loring, las obras definitivas del ferrocarril comenzaron en febrero de 1870 y se terminaron en $1873^{40}$. Desde el punto de vista financiero, lo más sobresaliente de esta construcción es que fue un negocio para sús constructores aún más saneado de lo que previeron en 1869.

Según las certificaciones de obras expedidas por la División de Sevilla, los datos financieros de la construcción fueron los siguientes:

a los derechos de aduanas, se abonará con arreglo al pliego de condiciones de la subasta.

7. Los constructores recibirán directamente todas las entregas de subvención y no podrán emplearlas más que en la construcción de las obras.

8." Solamente los nuevos constructores podrán proponer modificaciones de tarifas.

(Libro $10^{\circ}$ de Expediente de concesión y construcción, pp. 277 (reverso) a 279 (reverso).)

3 Escritura otorgada ante los Hermanos Larios, Hermanos Heredia y Hermanos Loring el 14 de agosto de 1867 ante el notario de Málaga don Miguel Cano de la Casa.

39 Exposición del Consejo de Administración de la Compañía del Ferrocarril de Córdoba-Espiel-Bélmez al ministro de Fomento en 15 de enero de 1872 . (Documentación citada.)

* Se autorizó la entrada en explotación de la línea en su totalidad el 28 de agosto de 1873, aun cuando no tenía todas las obras terminadas y no completo el material móvil. 
Coste de las obras y material fijo móvil ...... Subvención directa $\ldots \ldots . .7 .250 .000,00$ pts. Subvención adicional $\ldots . \quad 1.670 .464,91$ pts. $10.253 .179,32$ pts. Inversión privada $\ldots \ldots \ldots$ $8.920 .464,91$ pts. $(87 \%)$ $1.332 .714,14$ pts. $(13 \%)$

La diferencia con lo presupuestado en un principio fue tan grande porque los constructores malagueños consiguieron, primero, rebajar el presupuesto inicial de establecimiento ${ }^{41}$ con un nuevo proyecto en un 26,4 por $10{ }^{42}$; segundo, rebajar su propio presupuesto durante la construcción (obteniendo casi siempre la aprobación del Gobierno a las modificaciones que presentaron), y que ahorraron otro 22 por $100^{43}$, y, finalmente, dejaron sin construir (aun cuando el Estado les abonó la subvención íntegramente) el 6,6 por $100^{4}$.

"Al final el coste de establecimiento fue de 18.682.328 pesetas (obras iniciales + contrato de Gándara + contrato de Loring).

42 Que implicaba un trazado más corto, aprovechamiento de los adelantos técnicos para hacer un trazado más arriesgado y reducción del material de tracción y móvil a la mitad (relación anexa al contrato de construcción de Heredia, Larios y Loring).

43 Las modificaciones fueron: a) Asiento de vías: sustitución de traviesas de roble por otras de pino y en menor número; b) Obras de fábrica: se hizo el puente de los Pedroches de mampostería en lugar de hierro; c) Accesoios: se redujo el número y superficie de las casas de guarda; d) Estaciones: se limitó el número de vías y andenes, y la de Córdoba, por ser provisional, se dejó en precario (no sería construida hasta 1890 por la Cía. de los Andaluces); e) Material de tracción: se sustituyeron las máquinas previstas por otras más adecuadas a una línea con fuertes pendientes (de ténder-motor), en proporción de una por dos; f) Material móvil: los vagones aportados, además de en menor número, fueron de menor calidad y, en caso de los de viajeros, mucho más hacinados.

* Certificado del ingeniero jefe de la División de Sevilla sobre las obras y material que faltan en la línea Córdoba-Bélmez en virtud de la Orden del 15 de febrero de 1870:

Obras:

Estación defintiiva de Córdoba $\ldots \ldots \ldots \ldots \ldots \ldots$

$355.302,40$ pesetas

Material móvil:

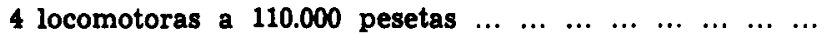

4 coches mixtos de $1 .^{*}$ y 2 . $^{2}$ clase a 11.250 pesetas ... ......

6 coches mixtos de 3 : $^{\circ}$ clase con freno a 7.500 pesetas ...

$440.000,00$

$45.000,00$

$45.000,00$

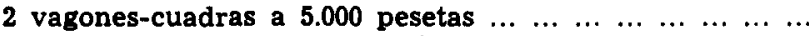

80 vagones-cuadras para carbón a 3.750 pesetas ... ... ...

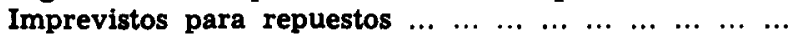

$10.000,00$

$300.000,00$

$122.500,00$

$\begin{array}{llllll}\text { Gastos imprevistos } 3 \% & \ldots & \ldots & \ldots & \ldots \\ \text { Idem. Admón. y Dirección } & 10 \% & \ldots & \ldots\end{array}$

$1.317 .802,40$

$39.534,07$

$131.780,24$

TOTAL

$1.489 .116,71$

(Documentación citada, año 1880.) 
Habida cuenta de las obras ejecutadas con anterioridad (2.432.328 pesetas), la parte de subvención abonada ( $1.322 .536,50$ pesetas) y la que los constructores debieron entregar a Gándara ( $667.463,50$ pesetas), los inversores malagueños obtuvieron por la sola construcción, una vez descontados los materiales no acopiados sobre el contrato (1.087.625), una ganancia neta de 5.341.322,60 pesetas, exponiendo un capital propio de $900.587,49$ pesetas y una pequeña cantidad para comprar algunas obligaciones con las que completar el depósito de garantía en manos del Gobierno ${ }^{45}$. Como tenían calculado, esa ganancia no la hicieron líquida al finalizar las obras, pues quedó un crédito a su favor contra la Sociedad del Ferrocarril C.-E.-B. de 7,3 millones de pesetas (importe del contrato menos subvención cobrada), pero ello les permitía, según las cláusulas del contrato de 1869 , pasar ellos a ser los únicos gestores del ferrocarril y explotarlo en provecho propio, a la vez que sobre esa cantidad iban acumulando un interés del 7 por 100, que llevó su crédito refaccionario a más de 10 millones en 1875 . Se puede decir que, como inversión, la construcción de este ferrocarril había sido un éxito para el gran capital malagueño, en mayor medida incluso que lo habían sido las líneas de Córdoba-Málaga y Bobadilla-Granada ${ }^{46}$.

La propia Administración republicana reconocería este hecho a través del jefe del Negociado:
«El Sr. Loring... con un desembolso que tal vez no llegue a 30 mil pesetas por $\mathrm{km}$. es dueño de una línea de $71 \mathrm{Kms...}$ que vendida puede dejarle una utilidad líquida de 7 u 8 millo- nes de pts.... el Estado puede decirse, que le ha regalado el camino para que lo venda o utilice por 99 años» ${ }^{47}$.

A partir de 1874, la historia de este ferrocarril fue similar a la de otras líneas en las que tenía participación el «Sindicato» malagueño. Ante las pesadas cargas financieras de la Sociedad del Ferrocarril C.-E.-B. y la asunción por los socios de la misma de la realidad de unos rendimientos menores a los soñados inicialmente (como consecuencia de los falsos cálculos de los años cincuenta, del comienzo de la crisis de la exportación andaluza en 1873 y de la mejora de los precios de adquisición de los carbones ingleses en un binterland costero más profundo), no era difícil para los constructores, ahora explotadores directos del ferrocarril, forzar la suspensión de pagos de la sociedad, eliminar al resto de los acreedores y quedarse, por tanto, con la

45 Las hubo de comprar el propio Loring ante la falta de recursos de la sociedad, aunque reconocería que no tenían prácticamente valor alguno.

46 Morilla Critz, J. (1978), pp. 173-177.

${ }^{47}$ Expediente de concesión, tomo 2, pp. 30-31 (reverso). 
línea completamente libre de cargas financieras. No iban a tener la oposición de unos socios que no podían soñar con obtener alguna vez beneficios que repartir ante las deudas que se habían ido acumulando y el tipo de contrato celebrado en 1869 con Heredia, Larios y Loring, que no contemplaba tan siquiera destinar una parte de los rendimientos de la explotación a remunerar a los miembros del Consejo de Administración y al personal de la sociedad.

La suspensión de pagos de la Sociedad del Ferrocarril C.-E.-B. fue decretada el 18 de mayo de 1875. En ese momento, el crédito de los constructores ascendía a 10.003 .523 pesetas, y el resto de las deudas por obligaciones, intereses, amortizaciones y otras menores (entre las que también estaban los constructores), a $2.816 .370,18$ pesetas. Lógicamente, la proposición presentada por la sociedad a los acreedores fue la de vender la línea en pública subasta y pagar por orden de prelación, en el que estaba en primer lugar el crédito refaccionario de los constructores.

De hecho, la aceptación del convenio dependía de estos últimos, que no lo asumieron hasta agosto de 1879 , en el momento en que el grupo malagueño estaba ya integrando, junto con capital francés, las líneas ferrnviarias de Andalucía en una sola empresa: la Compañia de los Ferrocarriles Andaluces $^{48}$. El 10 de enero de 1880 , el ferrocarril Córdoba-Bélmez fue rematado en subasta por 8.666 .670 pesetas, después de haber salido a un tipo de 13 millones, a favor de Antonio Reyna, que actuaba en nombre de Heredia, Larios y Loring, a quienes cedió el ferrocarril libre de toda carga, considerando éstos su importe como satisfacción del total de su crédito contra la extinguida sociedad (realmente, esa cantidad cubría el principal del crédito de construcción, las obligaciones y las acciones en poder del «Sindicato»).

Después de todas estas operaciones, las sociedades Heredia, Larios y Loring habían obtenido un ferrocarril valorado ahora en 8,5 millones de pesetas con una inversión de capital propio de aproximadamente 1,5 millones (obras, obligaciones en garantía al Gobierno, otros préstamos durante la explotación) ${ }^{4}$, lo que significaba que habían obtenido un beneficio final de todo ello de siete millones de pesetas, que representaba un rendimiento anual de casi el 52 por 100 y una capitalización de la cantidad inicial al cabo de los nueve años al tipo de casi el 18 por 100 anual, aparte, naturalmente, de los beneficios que les hubo de permitir realizar como propietarios de las minas de carbón de Bélmez la posesión del ferrocarril. Esa ganancia, además, fue hecha líquida en 1880 con el traspaso de la línea a los Ferrocarriles Andaluces, siguiendo sus constructores, por otra parte, como

4 Tedde, P. (1878 a), p. 36.

- Según escritura de cesión del ferrocarril a favor de D. Jorge Loring, el 4 de febrero de 1880, ante el notario de Madrid don Juan Cuervo y Abalos. 
beneficiarios de su explotación, al formar parte de la nueva sociedad propietaria.

\section{Reflexiones finales}

A la vista del análisis precedente, entendemos que cabrían hacerse las siguientes consideraciones, a modo de conclusión:

1. La acción del Estado en cuanto a la construcción de este ferrocarril fue inicialmente negativa, al conceder dos líneas paralelas en desigualdad de condiciones y por negarse a tener en cuenta criterios de racionalidad económica en los proyectos. A la vez, al conceder subvención para un proyecto de coste muv elevado y no variarla en lo sucesivo, permitió que entre 1863 y 1869 este ferrocarril fuera casi en exclusiva un motivo de especulación con la subvención estatal por parte de entidades muy débiles financieramente. Tras 1869, sin embargo, el mantenimiento de la subvención, la agilización de los trámites para su cobro y las facilidades dadas para variar los proyectos hicieron apetecible su construcción para unos promotores que contaran con crédito exterior, sin necesidad de arriesgar grandes capitales.

2. Desde entonces, el ferrocarril carbonero de Córdoba-Bélmez se construyó en un momento de favorables perspectivas para los criaderos del Sur, que coincidieron con la movilización de la riqueza minera y agrícola del interior de Andalucía, facilitada por la industrialización europea y la política librecambista española. La obtención de los productos metálicos semielaborados y su exportación, junto con los agrícolas, necesitaban de la nueva fuente de energía, que podía competir en las comarcas interiores con la importada. Fue en ese momento cuando el capital andaluz se interesó decididamente por este proyecto.

3." La evolución tecnológica de la industria ferroviaria entre 1856 y 1874 , el desarrollo de la ingeniería española, la depresión de los precios y la abundancia de la mano de obra desempleada ayudaron a hacer viable la realización de un proyecto que inicialmente se demostraba ser antieconómico por los expertos más prudentes.

4. Todas las anteriores circunstancias permitieron que la construcción de este ferrocarril se presentara en 1869 como una alternativa inversora muy rentable para el capital de la zona, que, además, no acabó defraudando a sus detentadores, aunque ello no se debiera tanto a los rendimientos de la línea cuanto a la capitalización de la inversión a costa del Estado y los anteriores inversionistas en la línea. Constituye, pues, la construcción de esta línea ferro- 
viaria uno de los ejemplos de las actividades alternativas que encontraron capitalistas andaluces que, en la primera mitad de siglo, llegaron a ser protagonistas de una cierta industrialización.

\section{BIBLIOGRAFIA}

Casares Alonso, Aníbal (1973): Estudio histórico-económico de las construcciones ferroviarias españolas en el siglo XIX, Madrid, Instituto Iberoamericano de Desarrollo Económico.

Cordero, Ramón, y Meśndez, Fernando (1978): "El sistema ferroviario español", en Los ferrocarriles en España, 1844-1943, vol. I, Madrid, Servicio de Estudios del Banco de España.

Fockt, Robert W. (1964): Railroads and American Economic. Essays in Econometric History, Baltimore Maryland, The John Hopkins Press (traducción en español con el título Los ferrocarriles y el crecimiento económico de Estados Unidos, Madrid, Ed. Tecnos, 1972).

Franco Quirós, Juan (1979): "Una nueva ciudad andaluza: Linares 1875", Actas del II Congreso de Historia de Andalucía. Andalucía contemporánea (siglos XIX y XX), tomo I, Córdoba, Publicaciones del Monte de Piedad y Caja de Ahorros de Córdoba, pp. 508-528.

Garcin Garcfa, Lorenzo (1979): "Propiedad minera y compañías en la cuenca hullera del río Guadiato", Actas del I Congreso de Historia de Andalucía. Andalucía contemporánea (siglos XIX y XX), tomo I, Córdoba, Publicaciones del Monte de Piedad y Caja de Ahorros de Córdoba, pp. 529-562.

Garcfa Montoro, Cristóbal (1978): Málaga en los comienzos de la industrialización: Manuel Agustín Heredia (1786-1846), Córdoba, Instituto de Historia de Andalucía.

Mateo del Peral, Diego (1978): "Los orígenes de la política ferroviaria en España (1844-1877)", en Los ferrocarriles en España, 1844-1943, vol. I, Madrid, Servicio de Estudios del Banco de España.

Mormla CrITz, José (1976): "Andalucía a fines del siglo xux: del capitalismo regional al capitalismo dependiente", Gibralfaro, núm. 28, año XXV, pp. 21-35.

- (1978): Gran capital y estancamiento económico en Andalucía. Acumulación de capital, Banca y ferrocarriles en Málaga, siglos XVIII y XIX, Córdoba, Instituto de Historia de Andalucía.

NADAL, Jordi (1972): "Industrialización y desindustrialización del sureste español, 1871-1913", Moneda y Crédito, núm. 120, marzo, pp. 3-80.

- (1975): El fracaso de la revolución industrial en España, 1814-1913, Barcelona, Editorial Ariel.

TrDDE, Piero (1978 a): "El proceso de formación de la Compañía de los Ferrocarriles Andaluces (1874-1880)", Hacienda Pública Española, núm. 35, pp. 390-395.

- (1978 b): "Las compañías ferroviarias en España (1835-1935)", en Ferrocarriles en España, 1844-1943, vol. II, Madrid, Servicio de Estudios del Banco de España.

TortellA, Gabriel (1975): Los origenes del capitalismo en España, Madrid, Ed. Tecnos (2." edición 1982).

- (1981): "La economía española, 1830-1900", en Historia de España, dirigida por Tuñón de Lara, vol. VIII, Barcelona, Ed. Labor.

WaIs, Francisco (1974): Historia de los ferrocarriles españoles (2." edición), Madrid, Iditora Nacional. 